\title{
Efeitos de Herbicidas na Atividade Fotossintética e no CRescimento de AbacAXI (Ananas comossus) ${ }^{1}$
}

\author{
Effects of Herbicides on the Photosynthetic Activity of Pineapple (Ananas comossus)
}

\author{
CATUNDA, M.G. ${ }^{2}$, FREITAS, S.P. ${ }^{3}$, OLIVEIRA, J.G. ${ }^{4}$ e SILVA, C.M.M. ${ }^{5}$
}

\begin{abstract}
RESUMO - O manejo de plantas daninhas na cultura do abacaxi é uma prática indispensável, sendo o controle químico cada vez mais utilizado, uma vez que permite o controle eficiente e não danifica as raízes da cultura. Todavia, há poucos trabalhos sobre interferência de herbicidas no crescimento da cultura; portanto, visando avaliar os efeitos de amicarbazone e diuron + paraquat, estes foram aplicados diretamente sobre as plantas, sendo os efeitos mensurados através da taxa de fluorescência da clorofila $a$ e dos teores de clorofila $a$, clorofila $b$ e carotenóides, além da avaliação de altura e biomassa seca de parte aérea ( $\left.\mathrm{W}_{\mathrm{pa}}\right)$. O herbicida amicarbazone promoveu declinio nos teores de pigmentos fotossintéticos, não se verificando a mesma interferência para as variáveis altura e $\mathrm{W}_{\mathrm{pa}}$; no entanto, o herbicida diuron + paraquat foi letal para a cultura, haja vista a redução nos teores de clorofilas $a$ e $b$ e carotenóides, além da impossibilidade da medição da altura e $\mathrm{W}_{\mathrm{pa}}$ (aos 120 DAT) em função da morte das plantas aos 30 DAT, o que demonstra certa seletividade do amicarbazone à cultura do abacaxi.
\end{abstract}

Palavras-chave: pigmentos fotossintéticos, fluorescência, amicarbazone, diuron, paraquat.

\begin{abstract}
Weed management in pineapple crop is an indispensable practice, with chemical control being increasingly used since it allows efficient control without injury to the roots. Since little literature is available on herbicide interference in crop growth, the aim of this work was to evaluate the effects of the herbicides amicarbazone and diuron + paraquat applied directly on the plants. The herbicide effects were measured by the fluorescence rate of chlorophyll a and chlorophyll a, chlorophyll $\mathrm{b}$ and carotenoid contents, and by evaluating the height and dry biomass of the aerial part $\left(W_{p a}\right)$. The application of amicarbazone reduced the photosynthetic pigment contents although the same interference in height and $W_{p a}$ variables was not observed; however, diuron + paraquat herbicide caused the death of the pineapple plants, indicating a reduction in chlorophyll $\mathrm{a}$ and $\mathrm{b}$ and carotenoids rendering it impossible to measure the height and $W_{p a}$ values (at 120 DAT) as a result of the death of the plants at 30 DAT, showing a certain amicarbazone selectivity for pineapple crop.
\end{abstract}

Key words: photosynthetic pigments, fluorescence, amicarbazone, diuron, paraquat.

\section{INTRODUÇÃO}

No cultivo do abacaxi, a competição com plantas daninhas é agravada, por ser uma cultura de pequeno porte e apresentar desenvolvimento vegetativo inicial muito lento, favorecendo a extração de água (principalmente em regiões sob longos veranicos) e nutrientes pelas plantas daninhas. Alta densidade (40 plantas $\mathrm{m}^{-2}$ ) de tiririca (Cyperus rotundus) e capim-colchão (Digitaria horizontalis) reduz significativamente os teores de nitrogênio, fósforo, potássio e cálcio na folha D do abacaxizeiro - folha mais jovem entre as folhas adultas e a mais ativa fisiologicamente (Cunha et al., 1999) - aos 30 dias

Recebido para publicação em 11.8.2004 e na forma revisada em 21.4.2005.

2 Doutoranda da UENF-CBB/LBCT; ${ }^{3}$ Prof. da UENF-CCTA/LFIT; ${ }^{4}$ Prof. da UENF-CCTA/LMGV; ${ }^{5}$ Doutorando, UENFCCTA/LFIT, Universidade Estadual do Norte Fluminense - UENF, 28013-602 Campos dos Goytacazes-RJ. 
de competição (Catunda \& Freitas, 2002). A redução destes e de outros nutrientes interfere na produtividade e na qualidade dos frutos produzidos.

Uma das alternativas de controle da competição é o uso de herbicidas, o que permite menor dependência de mão-de-obra (capinas); segundo Durigan (1982), durante o ciclo da cultura podem ser necessárias de 10 a 12 capinas, o que onera consideravelmente os custos de produção. Dentre os herbicidas utilizados, podem-se destacar aqueles que interferem na biossintese de clorofila, resultando em perda deste pigmento, e nos cloroplastos, alterando-os funcionalmente (Fayez, 2000). Esses compostos, além de interferirem na síntese de clorofila, também podem afetar a formação de outros pigmentos, como xantofilas (Váradi et al., 2000) e carotenóides (Kim et al., 2004), causando interferência no fluxo de elétrons (Wakabayashi \& Böger, 2004) e redução na produção de ATP por inibição da atividade da ATP-sintase no processo de fotofosforilação (Wakabayashi \& Böger, 1995).

O herbicida amicarbazone é um inibidor da fotossintese que se liga à proteína $\mathrm{D}_{1}$, não permitindo a transferência de elétrons entre as quinonas $A\left(Q_{A}\right)$ e $B\left(Q_{B}\right)$. Uma vez ligado o herbicida à proteína e estando a planta submetida a elevadas taxas de radiação fotossinteticamente ativa, a proteína $D_{1}$ é degradada proteolicamente (proteases presentes na membrana tilacoidial e no estroma), dado que a $Q_{B}$ reduzida reage com o oxigênio, resultando em oxigênio no estado "singlet", altamente energético. Este, por sua vez, reage com a água, formando peróxido de hidrogênio (Yamamoto, 2001), o qual promove peroxidação de membranas. A aplicação deste herbicida em plantas sensiveis causa redução do crescimento, clorose e necrose dos tecidos das folhas, podendo levar à morte da planta.

O diuron é um inibidor da transferência de elétrons no fotossistema II (PS II) que, segundo Fuerst \& Norman (1991), impede a redução da quinona $A$, por competir com a quinona $\mathrm{B}$ pelo sítio de ligação à proteína $\mathrm{D}_{1}$, $\mathrm{O}$ que ocasiona a saída de $Q_{B}$ e, conseqüentemente, interrupção no fluxo de elétrons, não permitindo com isso a redução do NADPH, a qual é essencial para a fixação de $\mathrm{CO}_{2}$ (Breitenbach et al., 2001). Por conseguinte, hă redução na geração de energia e nas taxas fotossintéticas, podendo resultar em aumento da emissão de fluorescência, além de causar morte dos tecidos verdes atingidos pelo produto.

Já o paraquat é um aceptor de elétrons auto-oxidado no fotossistema I (PS I) (Fujii et al., 1990) que em plantas expostas à luz pode levar a sérios prejuízos fisiológicos, como depleção de NADPH e inibição da fixação de $\mathrm{CO}_{2}$, em função da captura de elétrons de transição entre $\mathrm{Fe}_{\mathrm{SA}}$ e $\mathrm{Fe}_{\mathrm{SB}}$ do PS I; além disso, o radical paraquat formado reage diretamente com o oxigênio para produção de superóxidos, os quais promovem a destruição de membranas do cloroplasto por peroxidação destas (Preston et al., 1991).

No processo fotossintético, a luz é absorvida por pigmentos do complexo-antena, que, excitados, transferem energia para os centros de reação dos fotossistemas I e II $\left(\mathrm{P}_{700}\right.$ e $\mathrm{P}_{680}$, respectivamente) (Young \& Frank, 1996). Quando ocorre excesso de energia, esta pode ser dissipada na forma de fluorescência (Krause \& Winter, 1996). Portanto, uma das formas de monitoramento da inibição ou redução na transferência de elétrons entre os fotossistemas da planta sob estresse, que pode ser observada ainda em folhas intactas, é a fluorescência da clorofila (Maxwell \& Johnson, 2000), em que a redução na dissipação da energia pelo processo fotoquímico é refletida por incremento correspondente na fluorescência.

A análise da fluorescência da clorofila $a$ vem sendo largamente utilizada no entendimento dos mecanismos da fotossintese propriamente dito, bem como na avaliação da capacidade fotossintética alterada por estresses bióticos ou abióticos pelos quais as plantas possam passar, como temperatura (Oliveira et al., 2002), radiação (Mazza et al., 2000), deficiência hídrica (Roden \& Ball, 1996), salinidade (Belkhodja et al., 1994), presença de insetos (Bown et al., 2002) ou fungos (Peterson \& Aylor, 1995), herbicidas (Ireland et al., 1986) etc. Para esse tipo de avaliação são utilizados fluorômetros de luz modulada (Schreiber et al., 1996), cujas aplicações variam desde a rápida identificação de injúrias causadas ao aparelho fotossintético, mesmo quando o sintoma ainda não é visivel, até a análise detalhada da alteração da capacidade 
fotossintética da planta. Uma das grandes vantagens do uso deste método é o fato de a medição não ser destrutiva, sendo possível de se realizar tanto em laboratório quanto em campo.

A eficiência fotossintética máxima (ou rendimento quântico máximo do PS II) das plantas é dada pela razão $F_{v} / F_{m}$, em que $F_{m}$ é a fluorescência máxima e $F_{v}$ é a fluorescência variável, sendo esta obtida através da equação $\left(F_{m}-F_{0}\right)$, em que $F_{0}$ representa a fluorescência inicial, correspondente à fração da energia absorvida pelo complexo-antena e não transmitida, ou seja, não absorvida pelos pigmentos fotossintéticos (Rascher et al., 2000).

O teor de clorofila e carotenóides nas folhas também indica o nivel de dano que determinado estresse pode estar causando à planta, já que a clorose é, normalmente, um dos primeiros sintomas expressos. Hendry et al. (1987) relatam que em situações de estresse por herbicidas as clorofilas totais são destruídas com maior intensidade que os carotenóides; assim, a razão entre a concentração de clorofila total e a de carotenóides (CT/CAR) pode ser usada como um fator de avaliação de danos à planta.

Em virtude do exposto, este trabalho teve como objetivo avaliar os danos causados à atividade fotossintética após a aplicação dos herbicidas diuron + paraquat e amicarbazone, além dos efeitos destes sobre o crescimento das plantas de abacaxi.

\section{MATERIAL E MÉTODOS}

Realizou-se um ensaio em casa de vegetação no campus da Universidade Estadual do Norte Fluminense Darcy Ribeiro, no qual mudas de abacaxizeiro enraizadas foram transplantadas para vasos com capacidade de 15 litros, contendo substrato composto de solo, areia e esterco na proporção de 1:2:1, respectivamente. Após 30 dias de adaptação das mudas, os herbicidas amicarbazone e diuron + paraquat foram aplicados em área total, nas doses de 0,375 e 0,700 $\mathrm{kg} \mathrm{ha}^{-1}$ i.a., respectivamente. O monitoramento da fluorescência da clorofila a (através de fluorômetro de luz modulada, modelo Mini-Pam - Walz, Alemanha) e dos teores de pigmentos fotossintéticos foi realizado aos $1,2,3,4,5,6,7,10,15,20$ e
30 dias após a aplicação dos tratamentos (DAT).

As pinças para a medição da fluorescência da clorofila a foram colocadas no terço médio da folha D do abacaxizeiro, e a medição foi feita após 30 minutos de adaptação ao escuro, com emissão de um pulso de luz saturante de $0,3 \mathrm{~s}$, sob freqüência de $0,6 \mathrm{KHz}$, quando se avaliou também a fluorescência inicial $\left(\mathrm{F}_{0}\right)$, fluorescência máxima $\left(F_{m}\right)$ e a razão $F_{v} / F_{m}$. Nas mesmas folhas, foram retirados três discos de $8,5 \mathrm{~mm}$ de diâmetro, para determinação do teor de pigmentos fotossintéticos, utilizando o método de extração com o solvente orgânico DMSO (Hiscox \& Israelstam, 1979). Os discos foliares foram fatiados em pequenos pedaços, postos em tubos tipo "Falcon" e imersos em 3,0 $\mathrm{ml}$ de DMSO, os quais foram mantidos no escuro por 48 horas; após este período, realizaram-se as leituras em espectrofotômetro nas absorbâncias de 480, 649 e 665 nm (Wellburn, 1994).

Utilizaram-se as seguintes equações para determinar o conteúdo dos pigmentos fotossintéticos, de acordo com o proposto por Wellburn (1994):

$$
\begin{aligned}
{[\text { Clorofila } a]\left(\mu \mathrm{g} \mathrm{mL}^{-1}\right) } & =12,19 \mathrm{~A}_{665}-3,45 \mathrm{~A}_{649} \\
{[\text { Clorofila } b]\left(\mu \mathrm{gL}^{-1}\right) } & =21,99 \mathrm{~A}_{649}-5,32 \mathrm{~A}_{665} \\
\text { [Carotenóides] }\left(\mu \mathrm{g} \mathrm{mL} \mathrm{mL}^{-1}\right) & =\left(1000 \mathrm{~A}_{480}-2,14 \text { Clorofila } a\right. \\
& -70,16 \text { Clorofila } b) / 220
\end{aligned}
$$

Aos 120 DAT foram avaliados a altura das plantas e o comprimento da folha $\mathrm{D}$, sendo, posteriormente, as plantas secas em estufa a $70{ }^{\circ} \mathrm{C}$, com circulação de ar constante, por 72 horas, para determinação da biomassa seca da parte aérea $\left(\mathrm{W}_{\mathrm{pa}}\right)$.

O delineamento experimental foi realizado em blocos ao acaso com cinco repetições em parcelas subdivididas, com a parcela representando os herbicidas (controle, amicarbazone e diuron+paraquat) e as subparcelas, as 11 épocas de medição. Os dados foram submetidos à análise de variância, com posterior comparação de médias, utilizando o teste de Tukey a $5 \%$ de probabilidade.

\section{RESULTADOS E DISCUSSÃO}

Os valores encontrados para a razão clorofila total e carotenóides (CT/CAR) mostraram

Planta Daninha, Viçosa-MG, v. 23, n. 1, p. 115-121, 2005 
que apenas o herbicida diuron + paraquat proporcionou médias de CT/CAR menores que as do controle (Tabela 1), sendo visiveis sintomas de clorose intensa e necrose dos tecidos ainda nos primeiros dias após a aplicação. Intensa clorose ocorre em plantas de tabaco (Nicotiana tabacum) expostas à elevada luminosidade $\left(1.600 \mu \mathrm{mol} \mathrm{m} \mathrm{m}^{-2} \mathrm{~s}^{-1}\right), 24$ horas após aplicação de 50,0 $\mu \mathrm{M}$ de paraquat, causando destruição de clorofilas e peroxidação de membranas em função do excesso de oxigênio "singlet" $\left(\mathrm{O}_{2}{ }^{-}\right)$produzido (Miyagawa et al., 2000).

Tabela 1 - Valores médios da razão clorofila total e carotenóides (CT/CAR) e dos teores de clorofilas $a$ $($ Clo $a), b($ Clo $b$ ) e carotenóides (Car), aos 30 DAT

\begin{tabular}{|l|c|c|c|c|}
\hline \multirow{2}{*}{ Tratamento } & Clo $a$ & Clo $b$ & Car & CT/CAR \\
\cline { 2 - 5 } & \multicolumn{4}{|c|}{$\left(\mu \mathrm{g} \mathrm{mm}^{-2}\right)$} \\
\hline Controle & $0,361 \mathrm{a}$ & $0,134 \mathrm{a}$ & $0,073 \mathrm{a}$ & $6,026 \mathrm{a}$ \\
\hline Amicarbazone & $0,306 \mathrm{~b}$ & $0,117 \mathrm{~b}$ & $0,068 \mathrm{a}$ & $5,913 \mathrm{a}$ \\
\hline Diuron+paraquat & $0,071 \mathrm{c}$ & $0,020 \mathrm{c}$ & $0,005 \mathrm{~b}$ & $3,291 \mathrm{~b}$ \\
\hline
\end{tabular}

Médias seguidas por letras diferentes, na coluna, diferem entre si a 5\% de significância pelo teste de Tukey.

Tanto na presença de amicarbazone quanto na de diuron, o sistema de proteção fotossintético, dado pelos carotenóides, é sobrepujado pelo excesso de clorofila no estado de energia tríplice, em razão de os herbicidas se ligarem à proteína $\mathrm{D}_{1}$ do $\mathrm{PS}$ II, interrompendo o fluxo de elétrons (Depka et al., 1998). Dessa forma, a clorofila com carga triplice, em presença de oxigênio, leva à peroxidação de membranas do cloroplasto (Durrant et al., 1990), devido à formação de peróxido de hidrogênio, explicando assim o aparecimento de clorose foliar, com evolução para necrose, à medida que o processo atinge a parede celular (Hess \& Weller, 2000a). No entanto, quando se adiciona o paraquat, há potencialização final do processo, pelo fato de os primeiros promoverem maior translocação deste na planta, resultando em peroxidação de lipídios, o que ocasiona vazamento do suco celular e morte do tecido (Hess \& Weller, 2000b); neste caso, há interrupção do fluxo de elétrons em dois pontos da cadeia, no PS II e PS I, o que não ocorre quando se utiliza somente amicarbazone.
As plantas que receberam aplicação do herbicida amicarbazone, apesar de terem apresentado redução nos teores de clorofilas $a$ e $b$ (Tabela 1), não demonstraram toxicidade visível (clorose e necrose dos tecidos), resultado que foi confirmado com a análise da razão CT/CAR (Tabela 1, Figura 1A). No entanto, dados os valores de $F_{m}$, verifica-se que tanto o amicarbazone quanto diuron + paraquat proporcionaram o não-aproveitamento de parte da energia que chegava ao complexo-antena, uma vez que estes bloquearam o fluxo de elétrons na PS II em nível de proteína $D_{1}$ (amicarbazone e diuron) e no PS I em nível de ferredoxina (paraquat); assim, a energia foi dissipada na forma de fluorescência (Figura 1C).

Os tratamentos em que foram aplicados os herbicidas obtiveram médias de rendimento quântico máximo do PS II (quantificado através da razão $\mathrm{F}_{\mathrm{v}} / \mathrm{F}_{\mathrm{m}}$ ) menores que as do controle (Figura 1D), sugerindo redução no fluxo de elétrons; os valores encontrados para fluorescência máxima $\left(F_{m}\right)$ seguiram o mesmo padrão da razão $\mathrm{F}_{\mathrm{v}} / \mathrm{F}_{\mathrm{m}}$ (Figura $1 \mathrm{C}$ ), o que implica dizer que houve redução na quantidade de energia aproveitada pela planta para realização dos processos fotoquímicos, como fixação de $\mathrm{CO}_{2}$ e redução de NADPH.

O rendimento quântico máximo do PS II $\left(\mathrm{F}_{\mathrm{v}} / \mathrm{F}_{\mathrm{m}}\right)$ pode variar de 0,75 a 0,85 em plantas não submetidas a estresses (BòlharNordenkampf et al., 1989), sendo a redução desta razão um excelente indicador de efeito fotoinibitório quando as plantas estão submetidas ao estresse químico (Araus \& Hogan, 1994). Isso de fato ocorreu quando se utilizaram os herbicidas amicarbazone e diuron + paraquat, pois a razão $F_{v} / F_{m}$ foi da ordem de 0,66 e 0,19 (Tabela 2), respectivamente, enquanto para o controle obtevese o valor de 0,80. Logo, o tratamento diuron + paraquat causou maiores danos ao aparelho fotossintético das plantas de abacaxi, em comparação com o amicarbazone; para este, houve queda brusca no valor desta variável aos 5 DAT, porém, após 10 DAT, a razão $F_{v} / F_{m}$ voltou a subir, sugerindo que o herbicida tenha causado dano reversivel ao aparato fotossintético do abacaxizeiro e que a planta tenha conseguido se recuperar sem sintomas aparentes (Figura 1D). 

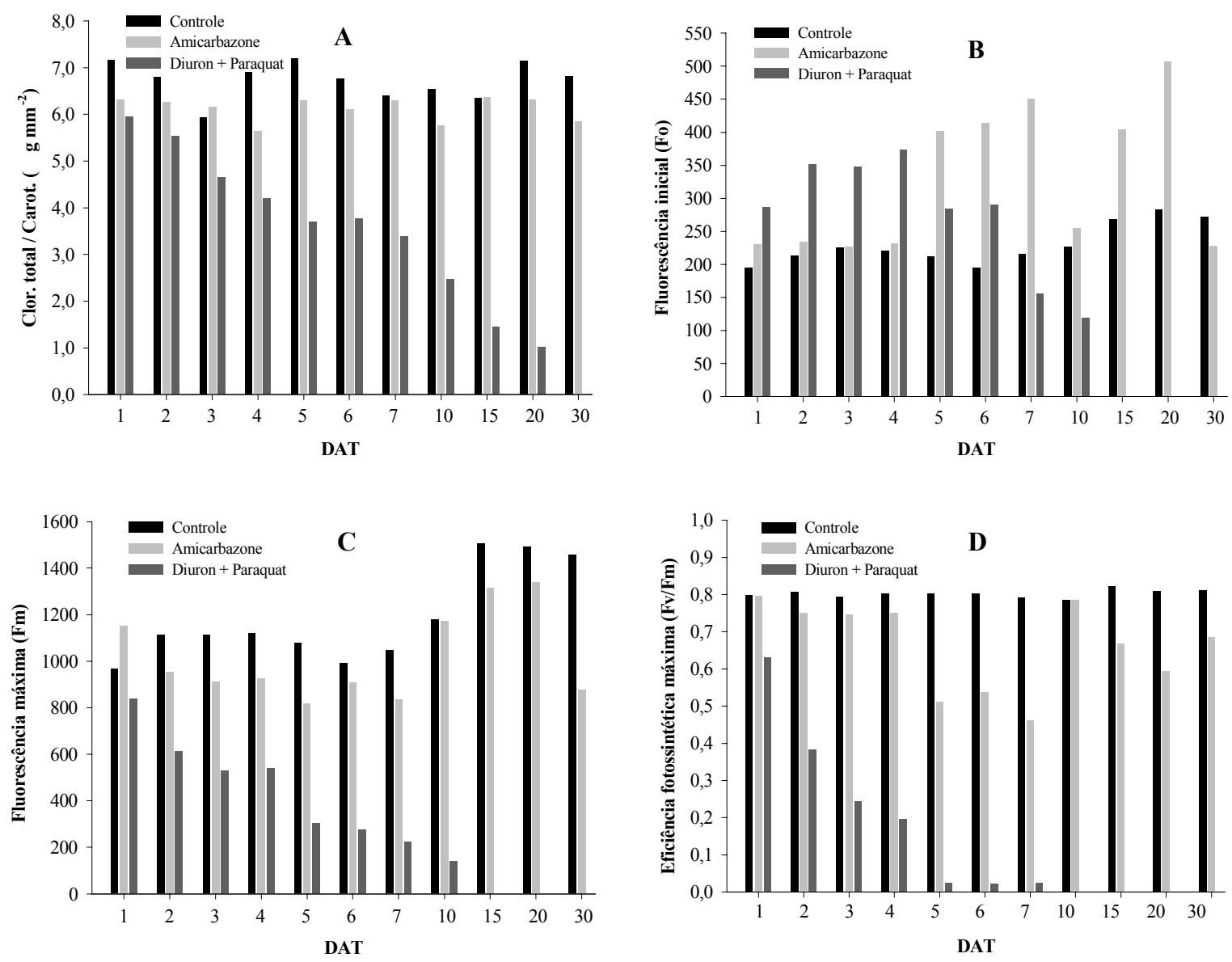

Figura 1 - Razão clorofila total/carotenóides (A), fluorescência inicial da clorofila $a$ (Fo) (B), fluorescência máxima da clorofila $a$ (Fm) $(\mathbf{C})$ e eficiência fotossintética máxima (razão Fv/Fm) (D) em plantas de $A$. comossus, em relação aos dias após aplicação dos tratamentos (DAT).

Tabela 2 - Valores médios da fluorescência inicial $\left(\mathrm{F}_{\mathrm{o}}\right)$, fluorescência máxima $\left(\mathrm{F}_{\mathrm{m}}\right)$ e eficiência fotossintética máxima $\left(\mathrm{F}_{\mathrm{v}} / \mathrm{F}_{\mathrm{m}}\right)$, aos $30 \mathrm{DAT}$

\begin{tabular}{|l|c|c|c|}
\hline \multicolumn{1}{|c|}{ Tratamento } & $\mathrm{F}_{\mathrm{o}}$ & $\mathrm{F}_{\mathrm{m}}$ & $\mathrm{F}_{\mathrm{v}} / \mathrm{F}_{\mathrm{m}}$ \\
\hline Controle & $230,473 \mathrm{~b}$ & $1.182,527 \mathrm{a}$ & $0,803 \mathrm{a}$ \\
\hline Amicarbazone & $324,764 \mathrm{a}$ & $1.220,182 \mathrm{~b}$ & $0,663 \mathrm{~b}$ \\
\hline Diuron+paraquat & $210,564 \mathrm{c}$ & $349,928 \mathrm{c}$ & $0,189 \mathrm{c}$ \\
\hline
\end{tabular}

Médias seguidas por letras diferentes, na coluna, diferem entre si a 5\% de significância pelo teste de Tukey.
Com relação ao comprimento das folhas D e $\mathrm{W}_{\mathrm{pa}}$ da cultura, os resultados indicam que não houve diferenças entre o amicarbazone e o controle, ou seja, os danos causados nos primeiros dias pelo herbicida não interferiram no crescimento final da planta (Tabela 3). No entanto, o herbicida diuron + paraquat causou danos severos às plantas de abacaxi, pois afetou a razão CT/CAR e, quando aplicado diretamente sobre as plantas, levou à morte destas, sendo estas descartadas aos 30 DAT.

Tabela 3 - Médias do comprimento da folha D (m), altura (m) e biomassa seca da parte aérea ( $\mathrm{g}$ ) ( $\left.\mathrm{W}_{\mathrm{pa}}\right)$ de plantas de abacaxi, aos 120 DAT

\begin{tabular}{|l|c|c|c|}
\hline Tratamento & Comprimento da folha D $(\mathrm{m})$ & Altura da planta $(\mathrm{m})$ & $\mathrm{W}_{\mathrm{pa}}(\mathrm{g})$ \\
\hline Controle & $0,788 \mathrm{a}$ & $1,183 \mathrm{a}$ & $222,500 \mathrm{a}$ \\
\hline Amicarbazone & $0,748 \mathrm{a}$ & $1,033 \mathrm{a}$ & $185,000 \mathrm{a}$ \\
\hline
\end{tabular}

Médias seguidas por letras diferentes, na coluna, diferem entre si a 5\% de significância pelo teste de Tukey. 
Portanto, o amicarbazone não provocou redução na razão entre os teores de clorofila total/carotenóides, mas resultou em queda na eficiência fotossintética máxima nos primeiros dias após aplicação; contudo, estes danos foram reversiveis, com a recuperação do aparelho fotossintético a partir dos 10 DAT. Além disso, os valores encontrados para altura da planta, comprimento da folha D e biomassa seca da parte aérea aos 120 DAT do herbicida amicarbazone mostram que não houve diferenças quando comparados aos do controle.

\section{LITERATURA CITADA}

ARAUS, J. L.; HOGAN, K. P. Comparative leaf structure and patterns of photoinhibition of the neotropical palms. Scheelea zonensis and Socratea durissima growing in clearing and forest understory during the dry season in Panama. Am. J. Bot., v. 81, n. 6, p. 726-738, 1994.

BELKHODJA, R. et al. Chlorophyll fluorescence as a possible tool for salinity tolerance screening in barley (Hordeum vulgare L.). Plant Physiol., v. 104, n. 2, p. 667673, 1994.

BOLHÀR-NORDENKAMPH, H. R. et al. Chlorophyll fluorescence as a probe of the photossinthetic competence of leaves in the field: a review of current instrumentation. Funct. Ecol., v. 3, n. 4, p. 497-514, 1989.

BOWN, A. W.; HALL, D. E.; MACGREGOR, K. B. Insect footsteps on leaves stimulate the accumulation of 4-aminobutyrate and can be visualized through increased chlorophyll fluorescence and superoxide production. Plant Physiol., v. 129, n. 4, p. 1430-1434, 2002.

BREITENBACH, J.; ZHU, C.; SANDMAN, G. Bleaching herbicide norflurazon inhibits phytoene desaturase by competition with the cofactors. J. Agric. Food Chem., v. 49, n. 11, p. 5270-5272, 2001.

CATUNDA, M. G.; FREITAS, S. P. Efeitos da competição de plantas daninhas na cultura do abacaxizeiro (Ananas comossus L.). In: CONGRESSO BRASILEIRO DE CIÊNCIA DAS PLANTAS DANINHAS, 23., 2002, Gramado. Resumos... Gramado: SBCPD, 2002. p. 533.

CUNHA, G. A. P.; CABRAL, J. R. S.; SOUZA, L. F. S. O abacaxizeiro: cultivo, agroindústria e economia. Brasília: EMBRAPA, 1999. 480 p.

DEPKA, B.; JAHNS, P.; TREBST, A. $\hat{a}$-carotene to zeaxanthin conversion in the rapid turnover of the D1 protein of photosystem II. FEBS Letters, v. 424, n. 3, p. $267-270,1998$

Planta Daninha, Viçosa-MG, v. 23, n. 1, p. 115-121, 2005
DURIGAN, J. C. Controle de plantas daninhas na cultura do abacaxi (Ananas comosus (L.) Merril). In: SIMPÓSIO BRASILEIRO SOBRE ABACAXICULTURA, 1., 1982, Jaboticabal. Resumos... Jaboticabal: FCAVJ/UNESP, 1982. p. $255-267$.

DURRANT, J. R. et al. Characterisation of tripler states in isolated photosystem II reaction centers: oxygen quenching as a mechanism for photodamage. Bioch. Biophys. Acta., v. 1017 , n. 1, p. 167-175, 1990 .

FAYEZ, K. A. Action of photosynthetic diuron herbicide on cell organelles and biochemical constituents of the leaves of two soybean cultivars. Pestic. Bioch. Physiol., v. 66, n. 2, p. 105-115, 2000.

FUERST, E. P.; NORMAN, M. A. Interactions of herbicides with photosynthetic electron transport. Weed Sci., v. 39, n. 3, p. 458-464, 1991.

FUJII, T. et al. The sites of electron donation of phosystem I to methyl viologen. Bioch. Biophys. Acta, v. 1015, n. 1, p. 41-48, 1990.

HENDRY, G. A. F.; HOUGHTON, J. D.; BROWN, S. B. The degradation of chlorophyll - a biological enigma. New Phytol., v. 107, n. 2, p. 255-302, 1987.

HESS, F. D.; WELLER, S. C. Mode of action in photosystem II: photosynthesis inhibitors (triazines, ureas, substituted phenols). In: HERBICIDE ACTION COURSE, 2000. West Lafayette: Purdue University, 2000a. p. 168186.

HESS, F. D.; WELLER, S. C. Mode of action in photosystem I (paraquat and diquat). In: HERBICIDE ACTION COURSE, 2000. West Lafayette: Purdue University, 2000b. p. 210-224.

HISCOX, J. D.; ISRAELSTAM, G. F. A method for the extraction of chlorophyll from leaf tissue without maceration. Can. J. Bot., v. 57, n. 12, p. 1332-1334, 1979.

IRELAND, C. R.; PERCIVAL, M. P.; BAKER, N. R. Modification of the induction of photosynthesis in wheat by glyphosate, an inhibitor of amino acid metabolism. J. Exp. Bot., v. 37, n. 176, p. 299-308, 1986.

KIM, J. S. et al. Death mechanisms caused by carotenoid biosynthesis inhibitors in green and in undeveloped plant tissues. Pest. Bioch. Physiol., v. 78, n. 3, p. 127-139, 2004.

KRAUSE, G. H.; WINTER, K. Photoinhibition of photosynthesis in plants growing in natural tropical forest gaps: a chlorophyll fluorescence study. Bot. Acta, v. 109, n. 6, p. 456-462, 1996.

MAXWELL, K.; JOHNSON, G. N. Chlorophyll fluorescence: a practical guide. J. Exp. Bot., v. 51, n. 345, p. 659-668, 2000. 
MAZZA, C. A. et al. Functional significance and induction by solar radiation of ultraviolet-absorbing sunscreens in field-grown soybean crops. Plant Physiol., v. 122, n. 1, p. $117-126,2000$.

MIYAGAWA, Y.; TAMOI, M.; SHIGEOKA, S. Evaluation of the defense system in chloroplasts to photooxidative stress caused by paraquat using transgenic tobacco plants expressing catalase from Escherichia coli. Plant Cell Physiol., v. 41, n. 3, p. 311-320, 2000.

OLIVEIRA, J. G.; ALVES, P. L. C. A.; MAGALHÃES, A. C. The effect of chilling on the photosynthethic activith in coffe (Coffea arabica L.) seedlings. The protective action of chloroplastid pigments. Braz. J. Plant Physiol., v. 14, n. 2, p. $95-104,2002$.

PETERSON, R. B.; AYLOR, D. E. Chlorophyll fluorescence induction in leaves of Phaseolus vulgaris infected with bean rust (Uromyces appendiculatus). Plant Physiol., v. 108, n. 1, p. 163-171, 1995.

PRESTON, C.; HOLTUM, J. A. M.; POWLES, S. B. Resistance to the herbicide paraquat and increased tolerance to photoinhibition are not correlated in several weed species. Plant Physiol., v. 96, n. 2, p. 314-318, 1991.

RASCHER, U.; LIEBIG, M.; LÜTTGE, U. Evaluation of instant light-responses curves of chlorophyll parameters obtained with a portable chlorophyll fluorometer on site in the field. Plant Cell Environ., v. 23, n. 12, p. 1397-1405, 2000 .

RODEN, J. S.; BALL, M. C. The effect of elevated $\left[\mathrm{CO}_{2}\right]$ on growth and photosynthesis of two eucalyptus species exposed to high temperatures and water deficits. Plant Physiol., v. 111, n. 3, p. 909-919, 1996.
SCHREIBER, U. et al. Measurement of chlorophyll fluorescence within leaves using a modified PAM fluorometer with a fiber-optic microprobe. Photosy. Res., v. 47, n. 1, p. 103-109, 1996.

VÁRADI, G.; DARKÓ, E.; LEHOCZKI, E. Changes in the xanthophyll cycle and fluorescence quenching indicate lightdependent early events in the action of paraquat and the mechanism of resistance to paraquat in Erigeron canadensis (L.) Cronq. Plant Physiol., v. 123, n. 4, p. 1459-1469, 2000 .

WAKABAYASHI, K.; BÖGER, P. Peroxidizing herbicides (II): structure-activity relationship and molecular design.

Z. Naturforsch. C: Biosci., v. 50, n. 9-10, p. 591-601, 1995.

WAKABAYASHI, K.; BÖGER, P. Phytotoxic sites of action for molecular design of modern herbicides (Part 1): the photosynthetic electron transport system. Weed Biol. Manag., v. 4, n. 1, p. 8-18, 2004.

WELLBURN, A. R. The spectral determination of chlorophylls $a$ and $b$, as well as total carotenoids, using various solvents with spectrophotometers of different resolution. J. Plant Physiol., v. 144, n. 3, p. 307-313, 1994.

YAMAMOTO, Y. Quality control of photosystem II. Plant Cell Physiol., v. 42, n. 2, p. 121-128, 2001.

YOUNG, A. L.; FRANK, H. A. Energy transfer reactions involving carotenoids: quenching of chlorophyll fluorescence. J. Photoch. Photobiol. B: Biol., v. 36, n. 1, p. 3-15, 1996. 